\title{
Continuous venovenous haemofiltration for the treatment of theophylline toxicity
}

\author{
J H Henderson, C A McKenzie, P J Hilton, R M Leach
}

\begin{abstract}
In patients with severe theophylline toxicity charcoal haemoperfusion is the recommended method for rapid reduction of serum theophylline levels. However, access to this technique is limited in most hospitals. This case report shows that continuous venovenous haemofiltration, a technique available in most hospitals, is an effective alternative to charcoal haemoperfusion.

(Thorax 2001;56:242-243)
\end{abstract}

Keywords: venovenous haemofiltration; theophylline toxicity

\section{Case report}

A 53 year old woman was admitted to hospital with severe theophylline toxicity after taking $22.4 \mathrm{~g}(56 \times 400 \mathrm{mg})$ of slow release theophylline tablets. Following admission she had a persistent sinus tachycardia (250 beats $/ \mathrm{min}$ ) resulting in left ventricular failure, intractable vomiting with haematemesis, hypokalaemia $\left(\mathrm{K}^{+} 2.6 \mathrm{mmol} / \mathrm{l}\right)$, and tremor. Serum theophylline levels continued to increase during the first 24 hours after admission so she was transferred to the intensive care unit (ICU) where she had a tonic-clonic seizure, aspirated, and required intubation and ventilation.

Our previous experience suggested that haemofiltration had been beneficial in two other patients with theophylline toxicity. Treatment with continuous venovenous haemofiltration $(\mathrm{CVVH})$ was started in this patient 32 hours after the initial theophylline ingestion. A

Department of Critical

Care Medicine, $\mathbf{S t}$

Thomas' Hospital,

London SE1 7EH, UK

$\mathrm{J}$ H Henderson

C A McKenzie

P J Hilton

R M Leach

Correspondence to:

Dr R M Leach

richard.leach@gstt.sthames.nhs.uk

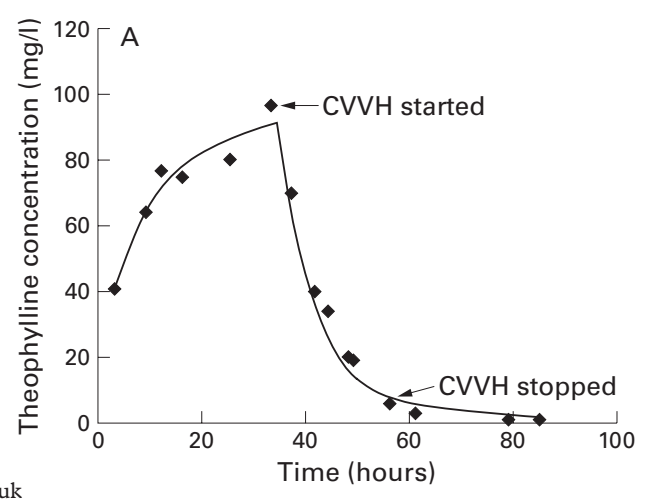

Figure 1 (A) Theophylline concentration ( $m g / l)$ before, during, and after CVVH. (B) Natural logarithm of theophylline concentration plotted against time. Before $(c-d)$ and after $(e-f) C V V H$ the pharmacokinetics of theophylline were non-linear. During (d-e) CVVH the pharmacokinetics were linear with an elimination constant $(K)$ of $0.118 / h$ (slope of $d-e)$ and an estimated half life of 5.87 hours.

Gambro HFM-10 haemofilter with a polyamide filter $\left(1.4 \mathrm{~m}^{2}\right)$ was used, with an average ultrafiltration rate of $25 \mathrm{ml} / \mathrm{min}$. Haemofilter circuits were primed with a bolus of 5000 units heparin and clotting was subsequently prevented with 1000 units heparin per hour. Sequential assays of serum theophylline levels were taken and measured using a high performance liquid chromatography (HPLC) assay. Theophylline levels were plotted against time before, during, and after haemofiltration (fig 1A). The natural logarithm of these values was also plotted against time to predict the patient's theophylline pharmacokinetics (fig 1B).

Twelve hours after the onset of haemofiltration the patient's vomiting had settled and she was started on oral activated charcoal (50 g four hourly). She had no further complications and haemofiltration was stopped after 24 hours. Theophylline levels fell rapidly from $96.4 \mathrm{mg} / 1$ at commencement to $6 \mathrm{mg} / 1$ on cessation of CVVH (fig 1A). After a further 24 hours she was discharged from the ICU and made a full recovery.

THEOPHYLLINE ABSORPTION AND CLEARANCE Theophylline is rapidly absorbed and, because of its short half life (1.4-12.8 hours), sustained release preparations are often used. In an overdose sustained release may result in toxicity for up to 24 hours after ingestion. ${ }^{1}$ Theophylline is metabolised by the cytochrome p450 enzyme system in the liver. ${ }^{2}$ Its metabolism can be described as biphasic pharmacokinetics or capacity limited metabolism. At normal and

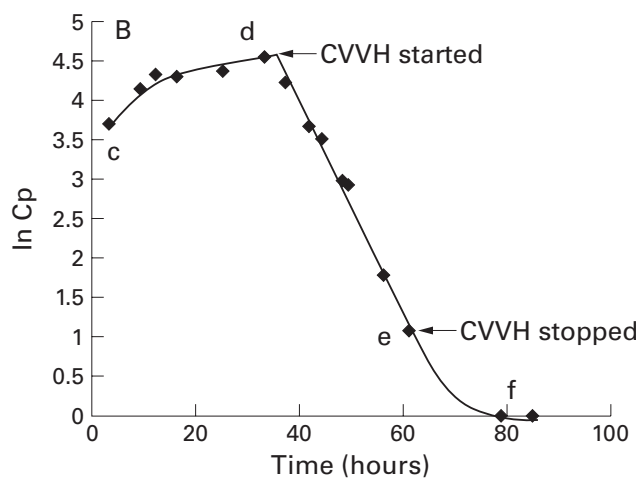

Received 31 March 2000 Accepted for publication 31 May 2000 
low therapeutic doses metabolism is linear and obeys first order kinetics. ${ }^{3}$ At higher doses, with concentrations at the top of the therapeutic range and in overdose, the enzyme system becomes capacity limited and results in nonlinear or zero order kinetics. ${ }^{4}$ The interpretation of overdose pharmacokinetics with slow release formulations such as theophylline is further complicated by continued drug absorption which will prolong the apparent half life. ${ }^{5}$

The maximum metabolic capacity of the enzyme system in 24 hours (Vmax) of theophylline is $1630-4397 \mathrm{mg} /$ day. $^{6}$ Our patient took $22400 \mathrm{mg}$ of theophylline, a dose well in excess of Vmax, and the enzyme system would be saturated resulting in non-linear pharmacokinetics. The increasing theophylline concentration before haemofiltration, which peaked at $96.4 \mathrm{mg} / 1$ (therapeutic range 10 $20 \mathrm{mg} / \mathrm{l}$ ) at 33 hours, reflects the zero order kinetics and the continued absorption of the slow release preparation (fig 1 ). These two factors prevent prediction of total body clearance. However, even if we assume that the Vmax was $4397 \mathrm{mg} /$ day, the apparent theophylline half life before haemofiltration could have been as long as five days. During haemofiltration there was a rapid change from non-linear to linear kinetics (fig 1B). The elimination rate constant $(\mathrm{K})$ on the haemofilter was $0.118 / \mathrm{h}$ (slope of the linear decay in fig $1 \mathrm{~B}$ ). The apparent half life for theophylline on the haemofilter is estimated at 5.87 hours. Increasing the ultrafiltration rate, which was not possible due to technical problems, would have reduced the apparent half life further.

\section{Discussion}

Theophylline is an important component of treatment for the management of reversible airways disease. Overdoses usually occur in patients with respiratory disease and management will often involve the respiratory physician. Toxicity can occur at levels as low as $15 \mathrm{mg} / \mathrm{l}^{4}$ Severe toxicity $(>80 \mathrm{mg} / \mathrm{l})$ causes cardiac arrhythmias, hypotension, nausea, vomiting, and tremor. ${ }^{1}$ Convulsions, rhabdomyolysis, and acute renal failure can occur. ${ }^{1}$ Laboratory tests typically reveal hypokalaemia, hypercalcaemia, respiratory alkalosis, and metabolic acidosis. ${ }^{1}$

Currently recommended techniques to increase theophylline clearance are oral activated charcoal and charcoal haemoperfusion. Oral charcoal can double the rate of clearance ${ }^{7}$ and is recommended in any overdose greater than $1 \mathrm{~g} .{ }^{1}$ Charcoal haemoperfusion is recommended if there are persistent convulsions, intractable vomiting, haemodynamic instability, rapidly deteriorating condition, or theophylline levels greater than $80 \mathrm{mg} / 1 .{ }^{1}$ Haemoperfusion requires that blood is passed over semipermeable microcapsules containing absorbants such as activated charcoal in a suitable extracorporeal circuit. It removes protein bound and middle sized toxins. ${ }^{7}$

Haemofiltration involves the passage of blood down one side of a semipermeable membrane which allows water and solutes with a molecular weight up to 40000 to pass across the membrane by convective flow, as in glomerular filtration. ${ }^{8}$ The rate of removal of such a solute is proportional to its concentration in the blood and independent of its size. ${ }^{8}$ The advantage of haemofiltration over haemoperfusion and haemodialysis is that it can be performed for long periods in haemodynamically unstable patients, can remove solutes with a relatively large molecular mass (up to approximately $15000 \mathrm{Da}$ ), is more readily accessible in most hospitals, and costs less.

In theory, haemofiltration should benefit patients with toxic theophylline levels because the theophylline molecule has a low molecular mass (180 Da), a low volume of distribution $(<11 / \mathrm{kg})$, single compartment kinetics and a low endogenous clearance $(<4 \mathrm{ml} / \mathrm{min} / \mathrm{kg})$, and is not heavily protein bound $(\sim 40 \%){ }^{2}$ The use of haemofiltration in the treatment of theophylline toxicity has not been reported previously (Medline and Embase literature search). One report has described increased aminophylline clearance in an asthmatic patient with acute renal failure who required higher doses of aminophylline to achieve therapeutic levels when on continuous arteriovenous haemofiltration. ${ }^{9}$

Charcoal haemoperfusion is claimed to achieve the highest rate of theophylline removal with an expected fourfold increase in clearance. ${ }^{3}$ In this case, the rate of theophylline clearance from the body was significantly increased during haemofiltration by the associated change from linear to non-linear kinetics. This effect explains the patient's rapid recovery from a near fatal condition to discharge from the ICU within 24 hours. It is impossible in this case to predict the exact clearance before haemofiltration due to the combination of zero order kinetics and the continued absorption of the slow release preparation. Nevertheless, clearance was increased by at least fourfold.

Most physicians have little immediate access to the technique of charcoal haemoperfusion. In contrast, haemofiltration is readily available in most hospitals in the ICU. In combination with oral activated charcoal, it appears to be a realistic and practical alternative to charcoal haemoperfusion, particularly in the haemodynamically unstable patient with severe theophylline toxicity.

1 Guy's and St Thomas' NHS Trust Medical Toxicology Unit. Theophylline poisoning: clinical features and management. National Poisons Information Service Handout.

2 Dollery C, ed. Therapeutic drugs. Volume 2. Edinburgh: Churchill Livingstone, 1991

3 Heath A, Knudson K. Role of extracorporeal drug removal in acute theophylline poisoning: a review. Med Toxicol 1987; 2:294-308.

4 Butts JD, Bradley S, Berger R. Non-linear pharmacokinetics: a preventable cause of iatrogenic theo-
phylline toxic reactions. Arch Intern Med 1991;151:2073-7.

5 Gaudrealt P, Guay J. Theophylline poisoning: pharmacological consideration
col $1986 ; 1: 169-91$.

6 Dunn G. Nonlinear theophylline kinetics. Ann Pharmacother 1984;18:155-64.

7 Pond SM. Extracroporeal techiques in the treatment of poisoned patients. Med f A A ust 1991;154:617-22.

8 Forni LG, Hilton PJ. Continuous haemofiltration in the treatment of acute renal failure. N Engl f Med 1997;336: 1303-9.

9 Urquhart R, Edwards C. Increased theophylline clearance 